\title{
INTERAÇÃO DE FATORES BIOFÍSICOS E ANTRÓPICOS COM A DIVERSIDADE FLORÍSTICA NA INDICAÇÃO DE ÁREAS PARA CONSERVAÇÃO DO BIOMA CAATINGA
}

\section{Interaction among biophysical and human factors with flora diversity in the indication of areas for conservation of Caatinga biome}

Dr. Thomaz Correa e Castro Costa Empresa Brasileira de Pesquisa Agropecuária - Embrapa

Sete Lagoas/MG - Brasil thomaz@cnpms.embrapa.br

Dr. Luciano José de Oliveira Accioly Empresa Brasileira de Pesquisa Agropecuária - Embrapa

Rio de Janeiro/RJ - Brasil luciano@uep.cnps.embrapa.br

Dra. Luciana Mara Temponi Oliveira Instituto Brasileiro de Geografia e Estatística - IBGE

Rio de Janeiro/RJ - Brasil temponi@ibge.gov.br

Dra. Maria Aparecida José de Oliveira Prof ${ }^{a}$. Adjunto I do Instituto de Biologia/ Universidade Federal da Bahia Salvador/BA - Brasil maparecida@ufba.br

Dr. Daniel Pereira Guimarães Empresa Brasileira de Pesquisa Agropecuária - Embrapa Sete Lagoas/MG - Brasil daniel@cnpms.embrapa.br

Artigo recebido para publicação em 12/09/2008 e aceito para publicação em 02/03/2009

RESUMO: $\quad$ Adiversidade floristica da caatinga foi relacionada com fatores biofísicos e antrópicos para indicação de áreas para conservação. Utilizou-se a análise multicritério para indicar regiões favoráveis à maior diversidade, por meio de fatores biofísicos, e regiões com menor pressão antrópica, a partir de variáveis sócio-econômicas extraídas do censo agropecuário. Os resultados foram comparados com inventários florísticos, fitossociológicos e de biomassa, no qual alguns fatores apresentaram relações significativas com a diversidade florística da caatinga. As áreas indicadas por estes fatores foram analisadas conjuntamente com fatores antrópicos, indicando-se áreas potenciais para conservação no Bioma Caatinga. 
Palavras-chave: Biodiversidade. Suporte à decisão. Desertificação. Unidade de Conservação.

\begin{abstract}
The flora diversity of caatinga biome was related to biophysical and human factors as an indication of conservation areas. Multicriteria analysis was used to indicate regions with favorable conditions for greater diversity, through biophysical factors, and regions with less human pressure, based on socioeconomic variables extracted from agricultural census. The results were compared with inventories of flora, phyto-sociology and biomass. Some biophysical factors showed significant relationships with the diversity of flora in the caatinga. The areas indicated by these factors were analyzed in conjunction with anthropic factors, thus allowing for the identification of potential areas for conservation in the Caatinga biome.
\end{abstract}

Key words: Biodiversity. Decision support. Desertification. Conservation Unit.

\section{Introdução}

O programa de ampliação do conhecimento dos biomas brasileiros para indicação de ações e áreas prioritárias para sua conservação (SILVA et al., 2004) levantou a importância da vegetação de caatinga para a conservação da biodiversidade brasileira, devido ao alto nível de endemismo de espécies. No entanto, a Caatinga tem o menor número e a menor extensão protegida dentre todos os biomas brasileiros (LEAL et al., 2005).

Os fatores físicos interferem no estabelecimento, permanência e dinâmica de táxons que constituem a flora potencial de um local, e no ritmo biológico das plantas do bioma, sobretudo no crescimento e na época de reprodução das espécies (MACHADO \& LOPES, 2002; ARAUJO \& FERRAZ, 2003). A precipitação pluviométrica influencia a distribuição das espécies e a produção de biomassa, assim como a localização geográfica, a configuração do relevo e as condições edáficas (fertilidade, teor de matéria orgânica, profundidade do solo, dentre outros) (SAMPAIO, 2003). Sobre as encostas e topos das chapadas e serras nos denominados "brejos de altitude" encontram-se as florestas mais úmidas, que recebem mais de $1.200 \mathrm{~mm}$ de chuvas (ANDRADE-LIMA, 1981; PRADO, 2003), em contraposição às formações de caatinga hiperxerófita, em regimes pluviométricos de até 600 $\mathrm{mm}$ anuais.
As variações da biomassa, vigor, bem como a estrutura da vegetação, são possíveis de serem estimadas em larga escala por meio de sensoriamento remoto. O índice de vegetação da diferença normalizada (NDVI) tem relação com a biomassa arbóreo - arbustiva da caatinga de forma que, quanto maior o vigor e a área foliar maior o valor do NDVI. Em tipologias florestais dos biomas Floresta Amazônica e Mata Atlântica, o NDVI satura em vegetações mais densas, mas no bioma Caatinga, com índice de área foliar geralmente abaixo de $4 \mathrm{~m}^{2} / \mathrm{m}^{2}$, é possível utilizá-lo para discriminar estados da vegetação, juntamente com outras variáveis biofísicas (COSTA et al. 2002).

Outra variável de sensoriamento remoto, a Fapar, mede a fração da radiação disponível em comprimentos de onda fotossinteticamente ativos (400 a $700 \mathrm{~nm}$ ) que a copa absorve, caracterizando o padrão de funcionamento da vegetação e a capacidade de absorver energia, podendo ser utilizada como estimador dos processos de fotossíntese e transpiração do dossel. Maiores valores de Fapar indicam maior atividade fotossintética da vegetação e maior produção de biomassa (OLIVEIRA, 2008).

Com relação aos fatores físicos, modelos probabilísticos de predição de tipologias florestais usando a temperatura, precipitação, elevação, declividade, aspecto e condições edáficas, para simular a vegetação potencial em florestas temperadas

Sociedade \& Natureza, Uberlândia, 21 (1): 19-37, ABR. 2009 
Interação de fatores biofísicos e antrópicos com a diversidade florística na indicação de áreas para conservação do bioma Caatinga Thomaz Correa e Castro Costa, Luciano José de Oliveira Accioly, Luciana Mara Temponi Oliveira, Maria Aparecida José de Oliveira, Daniel Pereira Guimarães

da Suíça (BRZEZIECKI et al. 1993) vem sendo experimentados. À antítese da modelagem para simulações da vegetação natural, está a pressão por atividades antrópicas, reduzindo a biomassa, a composição florística e alterando a estrutura da vegetação.

As atividades humanas substituem o ambiente natural nas áreas urbanas e, na zona rural, o reduzem na forma de mosaico. O uso da terra e as atividades sócio-econômicas da vizinhança são responsáveis pela magnitude da pressão sobre o fragmento florestal, resultando no grau de isolamento, efeito de borda, tamanho, forma e intervenção, que irão depreciar a estabilidade ecológica do fragmento, sendo a redução da diversidade potencial da região um dos indicadores de degradação (OLIVEIRA, 1997).

No semi-árido, as atividades que contribuem para a diminuição da diversidade potencial são: (1) corte raso da caatinga hiperxerófita, para atender a demanda de lenha; (2) cortes seletivos; (3) supressão para uso agrícola; (4) queima para limpeza da área. $\mathrm{O}$ posterior abandono destas áreas não garante o equilíbrio entre espécies, pois há exposição do solo e perda do banco de sementes (Vasconcelos Sobrinho, 1983, p. 31, citado por BRASIL, 2004); (5) predação de espécies vegetais pela pecuária (caprinos e bovinos), prejudicando, principalmente, a regeneração de algumas espécies.

Andrade et al. (2005) avaliaram a degradação em dois remanescentes da Caatinga com diferentes históricos de uso, no município de São João do Cariri - PB. No fragmento de caatinga arbórea conservada, mas utilizada para pastoreio de caprinos, foram registradas 14 espécies. Já no fragmento de caatinga degradada, com solo exposto e que anteriormente era utilizado para cultivo agrícola, e abandonado há 30 anos, encontrou-se seis espécies.

Similarmente, Maracajá et al. (2003), no município da Serra do Mel - RN, identificaram 14 espécies no fragmento preservado e sete espécies no fragmento antropizado por pastoreio e retirada de madeira para fins energéticos.
Com o objetivo de medir a interferência da componente antrópica na simulação da distribuição atual de comunidades de plantas, Fischer (1990) incorporou ao modelo probabilístico a variável "uso da terra" e Kazmierczak (1998) abordou a influência antrópica na degradação do ambiente, ensaiando uma modelagem da susceptibilidade à desertificação a partir da transformação de fatores ambientais e antrópicos por notas.

Os estudos sobre o processo desertificação, iniciados no Brasil na década de 1970, apontam para as proposições da Convenção das Nações Unidas de Combate a Desertificação (CCD) sobre os fatores determinantes da desertificação, "resultando esse processo mais da ação antrópica, do que de questões climáticas. Os determinantes climáticos atuariam como potencializadores das atividades humanas" (BRASIL, 2004).

Para estimar o estado de conservação da vegetação de uma região, dentre vários parâmetros, como o vigor, biomassa e sua estrutura, um indicador é a diversidade em tipologias vegetais, no caso a florística, pois, além de fornecer o número e as espécies da área em foco, pode ser extraída facilmente de inventários florestais. Na Caatinga há inúmeros inventários realizados, quer para estabelecer relações entre solo e a tipologia vegetal, quer para levantamento fitossociológico e da florística, quer para comparação da diversidade por similaridade (GOMES, 1980; SANTOS, 1987; FIGUEIREDO, 1987; SILVA, 1991; RODAL, 1992; ALCOFORADO FILHO, 1993a, ALCOFORADO FILHO et al. 2003b; ARAÚJO et al., 1995; MARACAJA et al., 2003; ROCHA et al., 2004; FARIAS \& CASTRO, 2004; AMORIM et al., 2005; ANDRADE et al, 2005; SANTANA \& SOUTO, 2006; COSTA et al. 2007), ou ainda, para inventariar as caatingas arbóreo arbustivas, de acordo com diretrizes da SUDENE (TAVARES et al., 1969a, 1969b, 1970, 1974a, 1974b; CARVALHO, 1975; TAVARES et al., 1975).

Estes inventários constituem uma base de dados valiosa que, relacionada com variáveis do meio físico, e com indicadores socioeconômicos, os quais 
refletem a pressão antrópica que contribui na perda de diversidade potencial, pode auxiliar na indicação de áreas para manutenção da diversidade potencial do Bioma Caatinga.

O objetivo deste trabalho foi indicar áreas para conservação no Bioma Caatinga, usando os fatores biofísicos, a diversidade florística arbóreoarbustiva da caatinga e os fatores antrópicos (agricultura, pecuária e extração vegetal).

\section{Material e métodos}

A área de estudo é o bioma Caatinga, que abrange a região semi-árida nordestina (IBGE, 1992). As variáveis biofísicas indicadoras de diversidade florística potencial da Caatinga do semi-árido nordestino foram:

Precipitação anual $(\mathbf{m m})$ : normais climatológicas calculadas a partir dos dados diários de precipitação, criticados e consistidos, com séries mínimas de 15 anos, dos postos pluviométricos da ANA. A espacialização foi realizada pela análise geoestatística para dados anisotrópicos, no Gstat, incorporado ao Idrisi (PEBEMA, 1998), com semivariogramas nas direções de maior e menor variabilidade, e interpolação por kriging ordinário, com sill para distância critica de seleção de pontos vizinhos.

Temperatura média anual $\left({ }^{\circ} \mathrm{C}\right)$ : as normais de temperatura foram obtidas de séries temporais com mínimo de cinco anos de dados de estações climatológicas do INMET. A temperatura média anual foi obtida a partir das normais de temperatura máxima, mínima e medida às $12 \mathrm{~h}$, e às $24 \mathrm{~h}$, pela fórmula:

$$
T_{\text {med }}=\left(T_{12 h}+T_{\text {max }}+T_{\text {min }}+2 . T_{24 h}\right) / 5
$$

A espacialização da temperatura media anual foi obtida por meio de equação de regressão linear múltipla, tendo como variáveis explicativas a longitude, latitude e altitude.

Índice de vegetação normalizado pela diferença (NDVI): foram utilizados dados médios anuais da série de dados EFAI-NDVI ("European
Fourier-Adjusted and Interpolated NDVI") (STÖCKLI, 2004), provenientes de filtragem e correção dos dados "Pathfinder" NDVI do sensor AVHRR do satélite NOAA, com resolução temporal de 10 dias e espacial de $0,1^{\circ} \times 0,1^{\circ}$, período de 1982 a 1999, cedida por Oliveira (2008).

Fração da radiação fotossinteticamente ativa absorvida pela vegetação (FAPAR): foram utilizados dados médios anuais de FAPAR calculados por Oliveira (2008), baseado em Stockli (2004).

Altitude (m) e declividade (\%): foram utilizados os dados SRTM corrigidos (NASA, 2005), e calculada a declividade percentual. Ambos foram reamostrados para a resolução espacial de $1440 \mathrm{x}$ $1440 \mathrm{~m}$.

Localização geográfica: as coordenadas geográficas latitude e longitude foram transportadas para atributos de pixels na resolução 1440 x 1440 m.

Para agregar os fatores físicos e obter um índice de favorecimento à diversidade florística $\left(\mathrm{S}_{1}\right)$, foi adotada a analise multicritério (MCE), associada à AHP (Analytical Hierarchy Process) (EASTMAN et al., 1995; TRIANTAPHYLLOU \& MANN, 1994), utilizando o software IDRISI.

Para o objetivo $\mathrm{S}$, os fatores $\left(\mathrm{x}_{\mathrm{i}}\right)$ foram selecionados pela significância da correlação do número de espécies com os fatores biofísicos. Os pesos $\left(\mathrm{w}_{\mathrm{i}}\right)$ foram calculados pela técnica AHP. Os fatores foram transformados e normalizados pela função fuzzy linear ascendente ou descendente na escala de 0-255 (byte), conforme a relação de pertinência com o número de espécies.

Na combinação linear da análise multicritério, o resultado é dado pela expressão: $S=\sum w_{i}{ }^{*} x_{i}$.

Os atributos considerados como pressão para a redução da diversidade florística foram extraídos das tabelas do SIDRA/IBGE, referentes ao Censo Agropecuário 1995-1996, e da Base de Informação Municipal do IBGE (BIM) (IBGE, 1996). As variáveis

Sociedade \& Natureza, Uberlândia, 21 (1): 19-37, ABR. 2009 
Interação de fatores biofísicos e antrópicos com a diversidade florística na indicação de áreas para conservação do bioma Caatinga Thomaz Correa e Castro Costa, Luciano José de Oliveira Accioly, Luciana Mara Temponi Oliveira, Maria Aparecida José de Oliveira, Daniel Pereira Guimarães

selecionadas (áreas de lavoura, pastagem, número de cabeças de gado, pessoal empregado na atividade agropecuária, máquinas, produção e investimentos e lucro), resultaram em 18 índices de atividade agropecuária normalizados pela área do município (Tab. 1).

Tabela 1. Índices da Atividade Agropecuária

\begin{tabular}{|c|c|c|}
\hline Variável original & Índice & Descriçãa \\
\hline LAVPERM & DLavPerm & Área de lavoura (permanente) / área municipal (ha) \\
\hline LAVTEMP & DLavTemp & Área de lavoura (temporária) / área municipal (ha) \\
\hline LAVTEMPD & DLavTempD & Área de lavoura em descanso (temporária) / área municipal (ha) \\
\hline TERPRNUTIL & DTerPrNUtil & Terras produtivas não utilizadas / área municipal (ha) \\
\hline PASTNAT & DPastNat & Área de pastagem (natural) / área municipal (ha) \\
\hline PASTPLAN & DPastPlan & Área de pastagem (plantada) / área municipal (ha) \\
\hline $\begin{array}{l}\text { PESSOAL } \\
\text { TRATOR } \\
\text { PLANTIO }\end{array}$ & DOcupRural & Pessoal ocupado na zona rural / área municipal (ha) \\
\hline $\begin{array}{l}\text { COLHEITA } \\
\text { CAMINHA } \\
\text { OUTILIT }\end{array}$ & Maquin & $\begin{array}{l}\text { Número de equipamentos (para plantio, para colheita, tratores, } \\
\text { caminhões, utilitários) na zona rural / área municipal (ha) }\end{array}$ \\
\hline Bov & Dbov Leivac & Número de cabeças bovinas / área municipal $\left(\mathrm{km}^{2}\right)$ \\
\hline LEI_VAC & & Litros de leite de vaca / área municipal (ha) \\
\hline Cap & DCap & Número de caprinos / área municipal $\left(\mathrm{km}^{2}\right)$ \\
\hline LEI_CAB & Leicap & Litros de leite de cabra / área municipal (ha) \\
\hline $\operatorname{CAVE}\left(\mathrm{m}^{3}\right)=\mathrm{CAVE}($ ton $)$ & & \\
\hline $\begin{array}{c}* 1000 * 3,33 * 0,001175 \\
\operatorname{LENH}\left(\mathrm{m}^{3}\right) \\
\operatorname{MADE}\left(\mathrm{m}^{3}\right)\end{array}$ & DExVe & $\begin{array}{l}\quad=(\text { Cave }+ \text { Lenh+Made }) / \text { área municipal (ha): } \\
\text { Índice de extração vegetal de carvão, lenha e madeira serrada }\end{array}$ \\
\hline VEGETAL & ValPrVeg & Valor da produção vegetal / área municipal (ha) \\
\hline ANIMAL & ValPrAnim & Valor da produção animal / área municipal (ha) \\
\hline VRINV & ValInvest & Valor dos investimentos / área municipal (ha) \\
\hline VRFIN & ValFinanc & Valor dos financiamentos / área municipal (ha) \\
\hline VRREC & Saldo & [VRREC (valor das receitas) - VRDES (valor das despesas)] \\
\hline VRDES & & / área municipal (há) \\
\hline
\end{tabular}

Estes índices foram integrados para gerar o índice de intensidade da atividade agropecuária $\left(\mathrm{S}_{2}\right)$, a média aritmética entre os fatores. Os atributos antrópicos foram normalizados pela função fuzzy linear ascendente.

\section{Validação}

O número de espécies foi a variável indicadora da diversidade florística do Bioma Caatinga, por ser viável sua obtenção em todos os levantamentos. Esta variável é menos sensível as diferentes abordagens dos inventários, que variam o diâmetro e a altura mínima coletada da planta, o método de amostragem, a intensidade da amostra, dentre outros.

Consultou-se 137 inventários, extraindo-se as seguintes informações: localização, temperatura média anual, precipitação anual, número de espécies arbóreo-arbustivas e outras características dos fragmentos. Para os levantamentos sem coordenadas geográficas e sem informação da localidade, utilizouse a sede do município. 
Dados de precipitação e de temperatura, quando não informados na publicação, foram obtidos de estações meteorológicas próximas. Inventários com a mesma localização foram listados com seus respectivos números de espécies, dando origem a duas listas: número mínimo e máximo de espécies, incorporando a fonte de variação da região e do grau de antropização.

Para validar os fatores físicos e agropecuários e calibrar os indicadores, as relações de $\mathrm{S}_{1}$ com a variável "número de espécies arbóreo - arbustivas" foram analisadas pelo coeficiente de correlação de postos de Spearman (SIEGEL, 1956) com níveis de probabilidade de rejeição, $p<0,05$, não paramétrico, evitando as pressuposições de normalidade dos dados.
Mesmo no caso de correlações significativas, optou-se pela análise multicriterial ao invés da regressão múltipla, pelo fato dos dados não atenderem as pressuposições para análise de regressão, como normalidade e ausência de multicolinearidade.

Utilizou-se também, na comparação com a favorabilidade à diversidade e a intensidade agropecuária, as Áreas Susceptíveis à Desertificação (ASD), definidas pelos parâmetros clima, solo, água e vegetação, associados à pressão exercida sobre os recursos naturais, pela ação antrópica (pressão populacional, formas inadequadas de uso e ocupação do solo, entre outros), que vêm contribuindo para a deflagração de processos de desertificação (Brasil 2004). Seis áreas foram identificadas pela Sudene com a colaboração do prof. Vasconcelos Sobrinho (Tab. 2).

Tabela 2. Áreas Piloto para investigação sobre a Desertificação no Semi-Árido Brasileiro (Brasil 2004).

\begin{tabular}{|l|l|l|l|}
\hline \multicolumn{1}{|c|}{$\begin{array}{c}\text { ÁREAS } \\
\text { PILOTO } \\
\text { SELECIONADAS }\end{array}$} & \multicolumn{1}{|c|}{ ESTADO } & $\begin{array}{c}\text { REGIÕES } \\
\text { NATURAIS E/OU } \\
\text { MICRORREGIÕES } \\
\text { HOMOGEENEAS }\end{array}$ & MUNICíPIOS \\
\hline 01 & Piauí & Caatinga e Cerrado & $\begin{array}{l}\text { Gilbués, Simplício Mendes, Cristino Castro, Ribeiro Gonçalves, } \\
\text { Correntes, Bom Jesus e municípios vizinhos. }\end{array}$ \\
\hline 02 & Ceará & Inhamuns ${ }^{30}$ & $\begin{array}{l}\text { Tauá, Ameiroz, Mombaça, Aiuaba, Catarina, Saboeiro, Irauçuba e } \\
\text { municípios vizinhos. }\end{array}$ \\
\hline 03 & $\begin{array}{l}\text { Rio Grande } \\
\text { do Norte }\end{array}$ & Seridó & $\begin{array}{l}\text { Currais Novos, Acari, Parelhas, Equador, Carnaúba dos Dantas, Caicó } \\
\text { e Jardim do Seridó. }\end{array}$ \\
\hline 05 & Paraíba & Cariris Velhos & $\begin{array}{l}\text { Juazeirinho, São João do Cariri, Serra Branca, Cabaceiras, Camalaú, } \\
\text { Picui e municípios vizinhos. }\end{array}$ \\
\hline 06 & Pernambuco & Sertão Central & $\begin{array}{l}\text { Salgueiro, Parnamirim, Cabrobó, Itacuruba, Belém do São Francisco, } \\
\text { Petrolina, Afrânio, Ouricuri, Araripina e municípios vizinhos. }\end{array}$ \\
\hline
\end{tabular}

FONTE: VASCONCELOS SOBRINHO, João. Desertificação no Nordeste do Brasil. Recife: Fadurpe/UFRPE. 2002.

Por fim foram combinados os objetivos $\mathrm{S}_{1} \mathrm{e}$ $\mathrm{S}_{2}$ para o zoneamento de áreas de conservação no bioma Caatinga. O fluxograma das operações descritas na metodologia é apresentado na Figura 1.


Figura 1. Fluxograma de Operações

Sociedade \& Natureza, Uberlândia, 21 (1): 19-37, ABR. 2009 


\section{Resultados e Discussão}

Na Fig. 2 é visualizada a distribuição dos inventários fitossociológicos, florísticos e de potencial madeireiro, utilizados na validação dos resultados.
Os Estados de Alagoas, Bahia, Ceará, Maranhão e Piauí apresentaram lacunas por este levantamento, e a maior concentração ocorreu nos Estados de Pernambuco, Paraíba e Rio Grande do Norte.

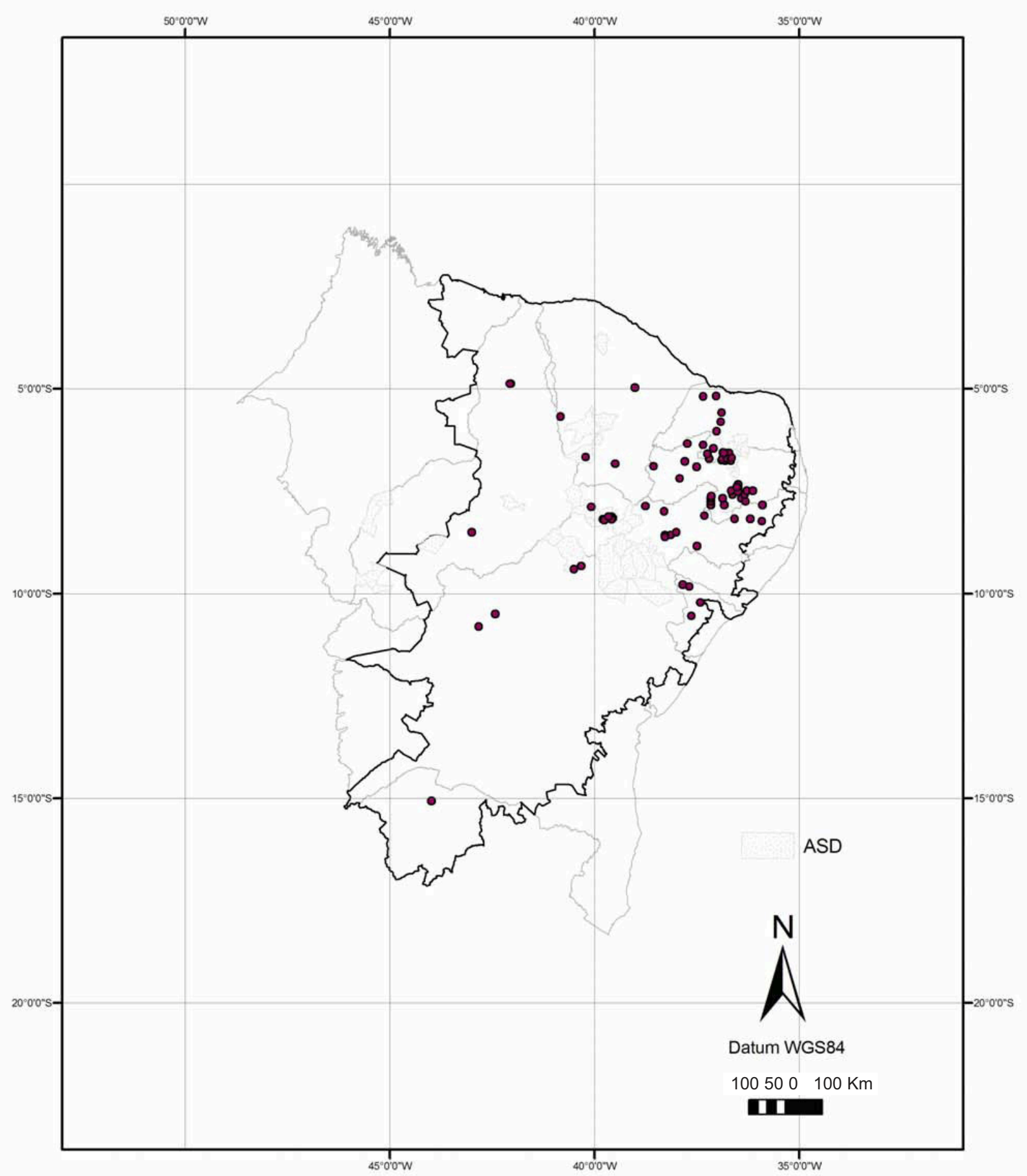

Figura 2. Localização de inventários realizados no bioma Caatinga e das Áreas Susceptíveis a Desertificação (ASD). 
Na relação do número de espécies arbóreoarbustivas da caatinga com a precipitação anual, a temperatura média anual e a altitude, constatou-se que condições naturais e antropismos interferem na diversidade de espécies arbóreo-arbustivas. Na Fig. 3, imaginando uma linha divisória com inclinação de $45^{\circ}$, verifica-se que, na região inferior direita do gráfico, ocorrem pontos que significam a ocorrência de uma baixa diversidade florística para condições favoráveis de precipitação, como nos municípios da região do Seridó, do Jaíba, Barbalha, com grande amplitude no número de espécies, o que não ocorre na região superior esquerda, embora, na extremidade inferior, dois inventários tenham registrado 11 espécies, um número potencial baixo, considerando a caatinga não antropizada, no Município de Cabaceiras-PB, de menor índice pluviométrico da região.

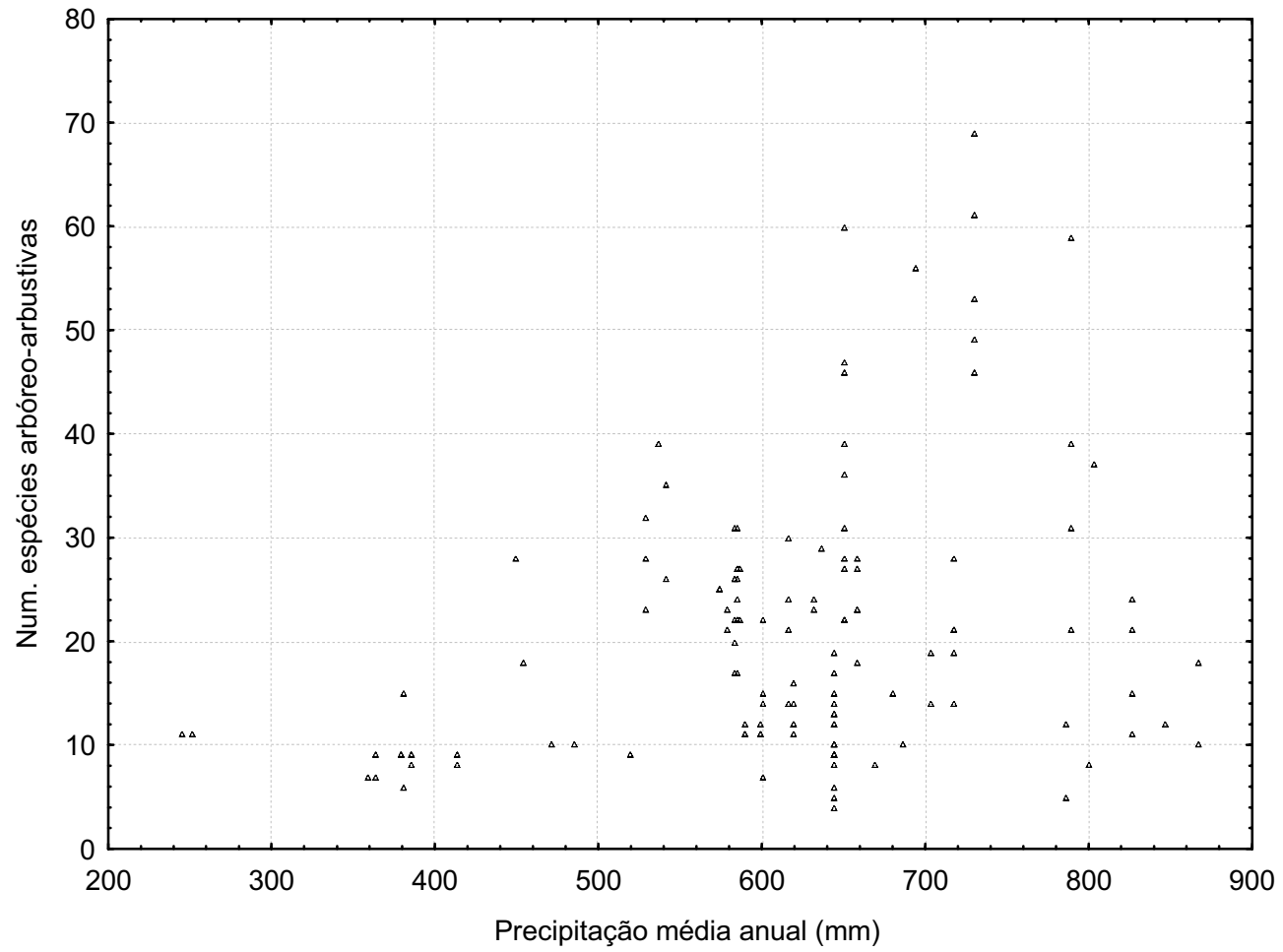

Figura 3. Precipitação média anual $(\mathrm{mm}) \mathrm{x}$ número de espécies arbóreo-arbustivas da caatinga $(\mathrm{n}=134$, Coef. Spearman=0.2428, $\mathrm{t}(\mathrm{n}-2)=2.87$, p-nível=0.004).

Para temperatura (Fig. 4) também se verifica esta tendência, ou seja, a região inferior esquerda do gráfico mostra pontos que significam a ocorrência de baixa diversidade florística para temperaturas mais amenas, pelo resultado de inventários que registraram grande amplitude no número de espécies para valores similares de temperatura, o que não ocorre na região superior direita.

Essas tendências levaram à hipótese de que fatores antrópicos estariam influenciando na redução da diversidade florística potencial.

Já a altitude, para a amplitude amostrada (Fig. 5), apresentou tendência com o maior número de espécies arbóreo - arbustivas ocorrendo nas faixas medianas de altitude. A altitude é determinante para os brejos de altitude nas condições de chuvas orográficas e temperaturas mais amenas, não sendo estes ambientes considerados, devido à escala de trabalho. 
Interação de fatores biofísicos e antrópicos com a diversidade florística na indicação de áreas para conservação do bioma Caatinga Thomaz Correa e Castro Costa, Luciano José de Oliveira Accioly, Luciana Mara Temponi Oliveira, Maria Aparecida José de Oliveira, Daniel Pereira Guimarães

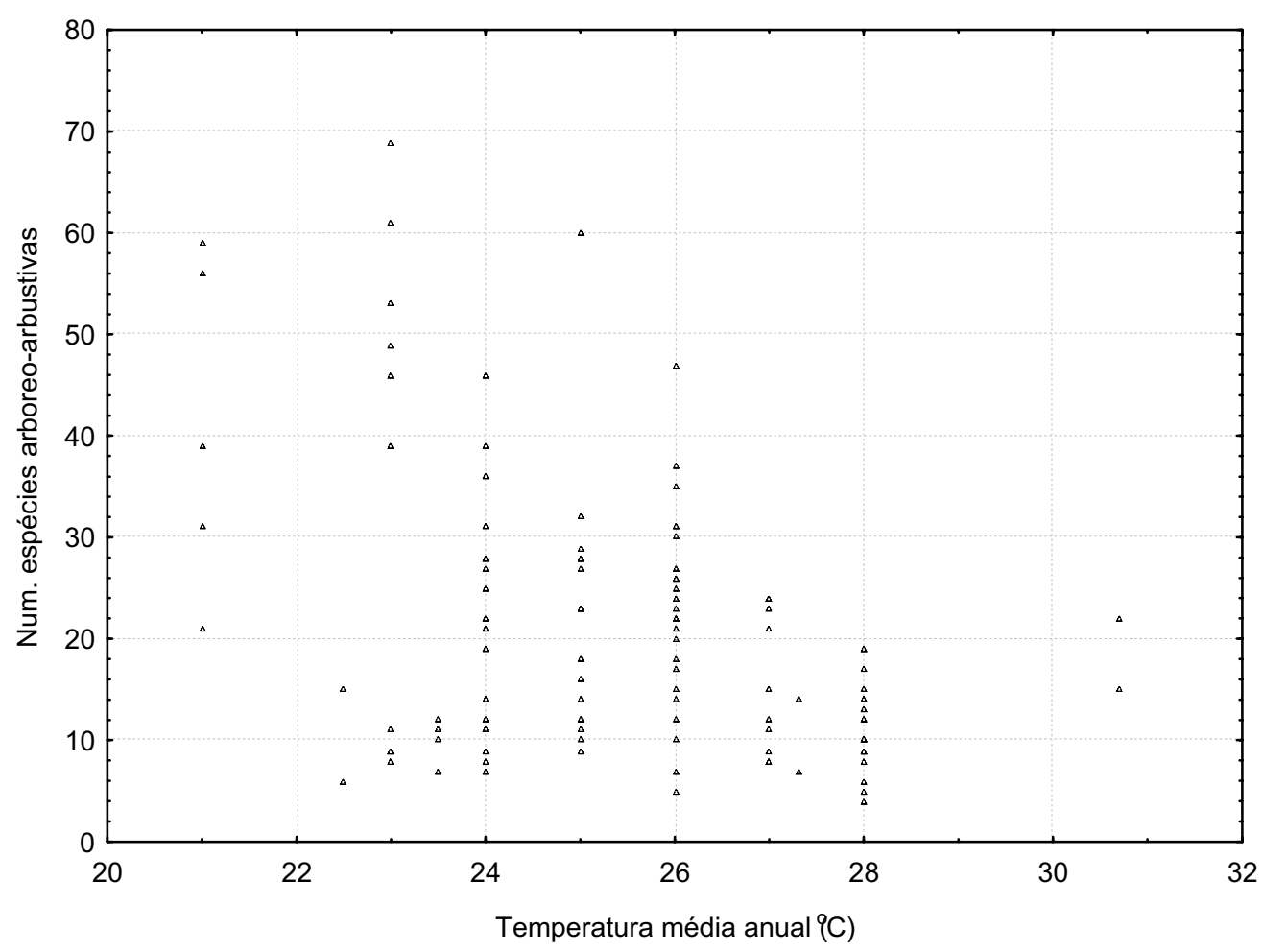

Figura 4. Temperatura média anual $\left({ }^{\circ} \mathrm{C}\right) \mathrm{x}$ número de espécies arbóreo-arbustivas da caatinga $(\mathrm{n}=134$, Coef. Spearman=$0.2751, \mathrm{t}(\mathrm{n}-2)=-3.28, \mathrm{p}$-nível $=0.001)$.



Figura 5. Altitude $(\mathrm{m}) \mathrm{x}$ Número de espécies arbóreo - arbustivas da caatinga $(\mathrm{n}=134$, Coef. Spearman=0.1247, $\mathrm{t}(\mathrm{n}-2)=$ 1.44, p-nível=0.150). 
As correlações do número de espécies arbóreo - arbustivas com os fatores biofísicos são apresentadas na Tab. 3. NDVI, FAPAR, precipitação anual e localização geográfica (latitude e longitude) correlacionaram-se significativamente com o número de espécies.

O NDVI obteve o maior índice, de 0,74 , com maiores valores próximos à transição do bioma Caatinga para outros biomas. AFAPAR obteve menor correlação quando comparada com o NDVI, o que era esperado, pois diferente do NDVI, este parâmetro é maior quando as características ambientais são ideais (insolação, ausência de fortes ventos, disponibilidade de água em concentrações ótimas e temperaturas médias).

E a precipitação, de grande importância para a diversidade florística, mesmo com correlação significativa, não obteve alto índice, possível pela erraticidade deste fenômeno, pelo grau de incerteza no processo de interpolação, pela distribuição das estações ou por outros condicionantes ambientais relacionados a oferta hídrica, como águas subterrâneas e fenômenos orográficos, com influência em regiões específicas, não considerados devido a escala de trabalho.

Tabela 3 - Correlações de Spearman entre o número máximo de espécies e os fatores físicos listados, n=84

\begin{tabular}{cccc}
\hline Fatores Físicos & Spearman & $\mathbf{t}(\mathbf{N}-2)$ & p-level \\
\hline NDVI & $0.745378^{*}$ & 10.12491 & 0.000000 \\
FAPAR & $0.417224^{*}$ & 4.15725 & 0.000079 \\
PPTANA & $0.458526^{*}$ & 4.67224 & 0.000012 \\
TMED & -0.113707 & -1.03638 & 0.303073 \\
ALT & 0.137468 & 1.25676 & 0.212409 \\
DECL & -0.161932 & -1.48597 & 0.141121 \\
LAT & $-0.528861^{*}$ & -5.64274 & 0.000000 \\
LON & $-0.533477^{*}$ & -5.71146 & 0.000000 \\
\hline
\end{tabular}

*correlações significativas $(\mathrm{p}<.05)$.

O fator temperatura média não foi significativo, em contraposição ao resultado com dados dos inventários. A equação obteve $\mathrm{R}^{2}=91,2 \%$ com altitude, longitude e latitude como variáveis explicativas, e boa homogeneidade entre dados observados e estimados. Os fatores de localização geográfica (latitude e longitude) obtiveram correlação com o número de espécies, indicando que a exposição, insolação, fatores térmicos, a maritmidade influenciam a diversidade florística.

Na Fig. 6 é apresentado o favorecimento à diversidade florística da caatinga pela integração dos fatores físicos significativos, pela análise multicritério, com um grau de importância maior para NDVI e precipitação, em relação aos demais fatores. Na Fig. 7 é apresentada a dispersão entre o favorecimento à diversidade florística e o número de espécies dos inventários, e o grau de qualidade da validação. Maiores valores do índice estão nos limites extremos do bioma Caatinga, ao noroeste do estado do Piauí, na Chapada da Diamantina, na Bahia, Chapada do Araripe, entre Pernambuco, Ceará e Paraíba, e no Norte de Minas, e os menores valores são, em grande parte, coincidentes com as áreas susceptíveis a desertificação. 
Interação de fatores biofísicos e antrópicos com a diversidade florística na indicação de áreas para conservação do bioma Caatinga Thomaz Correa e Castro Costa, Luciano José de Oliveira Accioly, Luciana Mara Temponi Oliveira, Maria Aparecida José de Oliveira, Daniel Pereira Guimarães

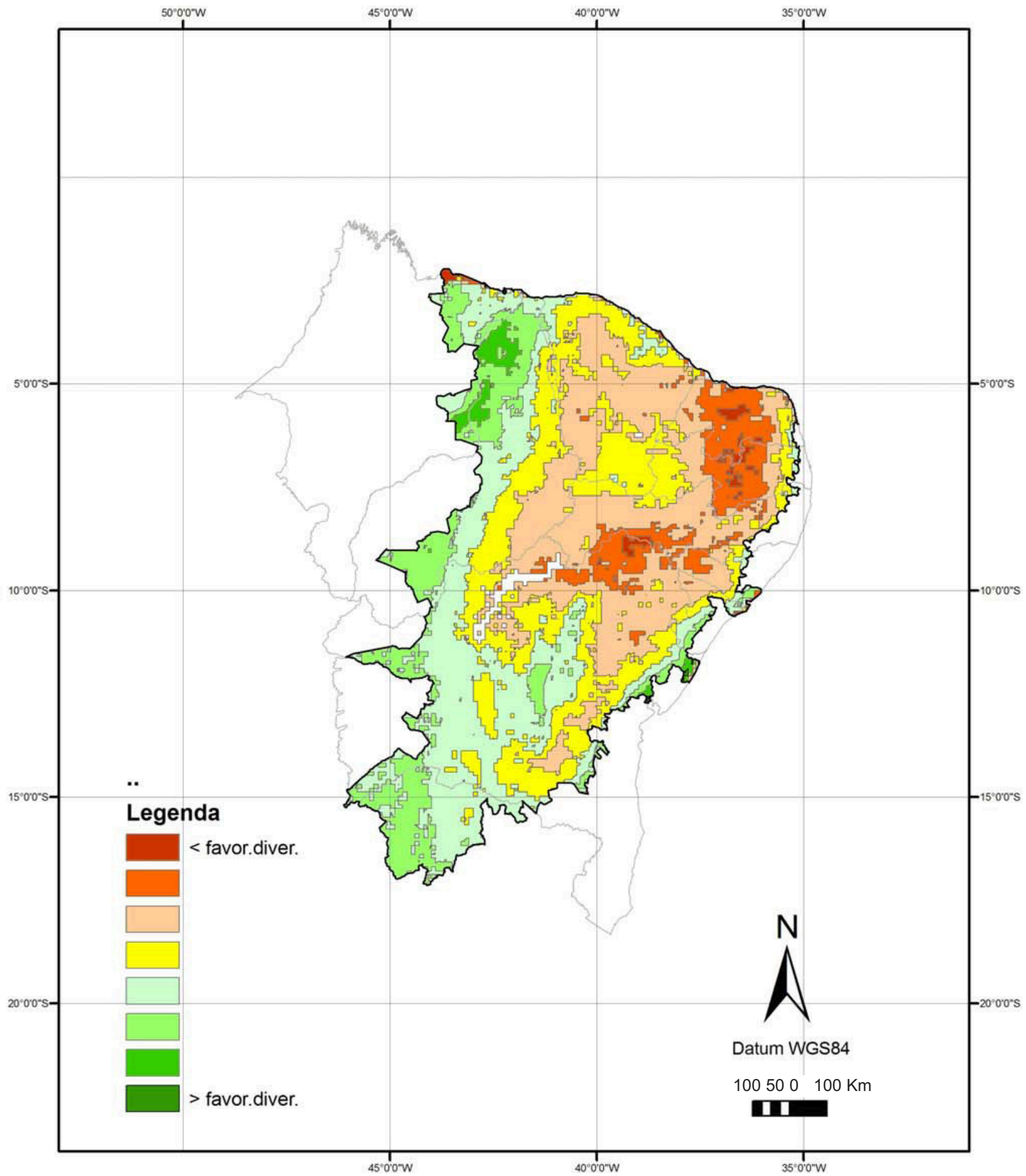

Figura 6. Favorecimento à diversidade florística do bioma Caatinga $(\mathrm{S} 1)=0.3333 *$ ndvi $+0.1111 *$ fapar $+0.3333 *$ ppt $+0.1111 *$ lat $+0.1111 *$ lon 




Figura 7 - Favorecimento à diversidade florística do bioma Caatinga (S1) x Número máximo de espécies arbóreo arbustivas por local $(n=84$, Coef. Spearman=0,7284, $t(n-2)=9,62$, p-nível=0.000).

Na correlação dos fatores agropecuários com o número mínimo de espécies (Tab. 4), coeficientes negativos significativos indicam que a maior magnitude da variável agropecuária está associada ao menor número de espécies, o que pode ser observado para lavoura permanente, pastagem natural, leite de vaca e máquinas. A baixa significância e relações inversas nas demais variáveis demonstram que as variáveis agropecuárias, na escala municipal, não foram sensíveis para indicar a perda de diversidade florística. As informações sócio-econômicas, embora eficazes na caracterização do uso e cobertura dado à área em questão, poderiam ter melhor acurácia com a diversidade florística, se obtidas em unidades de maior resolução (setores censitários) e na dinâmica temporal (censos agropecuários).

A não associação das variáveis agropecuárias com as áreas susceptíveis a desertificação, e principalmente com os núcleos de desertificação, se justifica pelo fato destas áreas serem resultantes de processos antrópicos históricos específicos, associados à condição de aridez (BRASIL, 2004), muitos iniciados antes do registro do primeiro censo agropecuário de 1940.

Grandes regiões que indicaram menor intensidade de atividades agropecuárias estão situadas no noroeste do Estado da Bahia, centro do Estado do Piauí, e nordeste do Maranhão (Fig. 8). A maior atividade agropecuária está concentrada na parte leste da região semi-árida, fronteira com o agreste.

Novos cenários, como a transposição do Rio São Francisco, podem mudar o paradigma de que a região semi-árida não é apta para o desenvolvimento econômico, e intensificar processos que levam a perda da diversidade florística. 
Tabela 4- Correlações de Spearman entre o número mínimo de espécies e os fatores agropecuários, n=84

\begin{tabular}{cccc}
\hline Fatores Agropecuários & Spearman & $\mathbf{t}(\mathbf{N}-2)$ & p-level \\
\hline DLAVPERM & $-0.315101^{*}$ & -3.00652 & 0.003507 \\
DLAVTEMP & -0.093268 & -0.84827 & 0.398755 \\
DLAVTEMD & -0.177422 & -1.63252 & 0.106404 \\
DTENUTIL & -0.177239 & -1.63079 & 0.106770 \\
DPASTNAT & $-0.325524^{*}$ & -3.11754 & 0.002515 \\
DPASPLAN & $0.413274^{*}$ & 4.10974 & 0.000093 \\
BOVKM2 & -0.143557 & -1.31357 & 0.192656 \\
CAPKM2 & -0.047101 & -0.42699 & 0.670506 \\
LEIVAC & $-0.240513^{*}$ & -2.24380 & 0.027541 \\
LEICAB & 0.153222 & 1.40406 & 0.164077 \\
MAQUIN & $-0.258727^{*}$ & -2.42545 & 0.017485 \\
DENSEXVE & -0.051526 & -0.46721 & 0.641592 \\
OCPRURAL & 0.078858 & 0.71632 & 0.475826 \\
VALPRVEG & 0.058229 & 0.52819 & 0.598797 \\
VALPRANI & -0.188864 & -1.74158 & 0.085333 \\
VALFINAN & 0.116936 & 1.06622 & 0.289455 \\
VALINVES & -0.088265 & -0.80240 & 0.424639 \\
SALDO & 0.153552 & 1.40716 & 0.163160 \\
\hline
\end{tabular}

*correlações significativas $(\mathrm{p}<.05)$

Na Fig. 9 é apresentado o resultado do favorecimento à diversidade florística com a intensidade da atividade agropecuária. Áreas com menor intensidade e maior favorecimento podem ser Quintos, situada no Seridó, no Estado do Rio Grande do Norte, abordada com detalhes em Costa et al. indicadas em políticas de criação de unidades de conservação. Embora as grandes manchas situem-se na parte oeste e sul do bioma Caatinga, pequenas manchas ocorrem por todo o bioma. A Serra dos (2008), é uma das áreas selecionadas por esta metodologia. 
Interação de fatores biofísicos e antrópicos com a diversidade florística na indicação de áreas para conservação do bioma Caatinga Thomaz Correa e Castro Costa, Luciano José de Oliveira Accioly, Luciana Mara Temponi Oliveira,

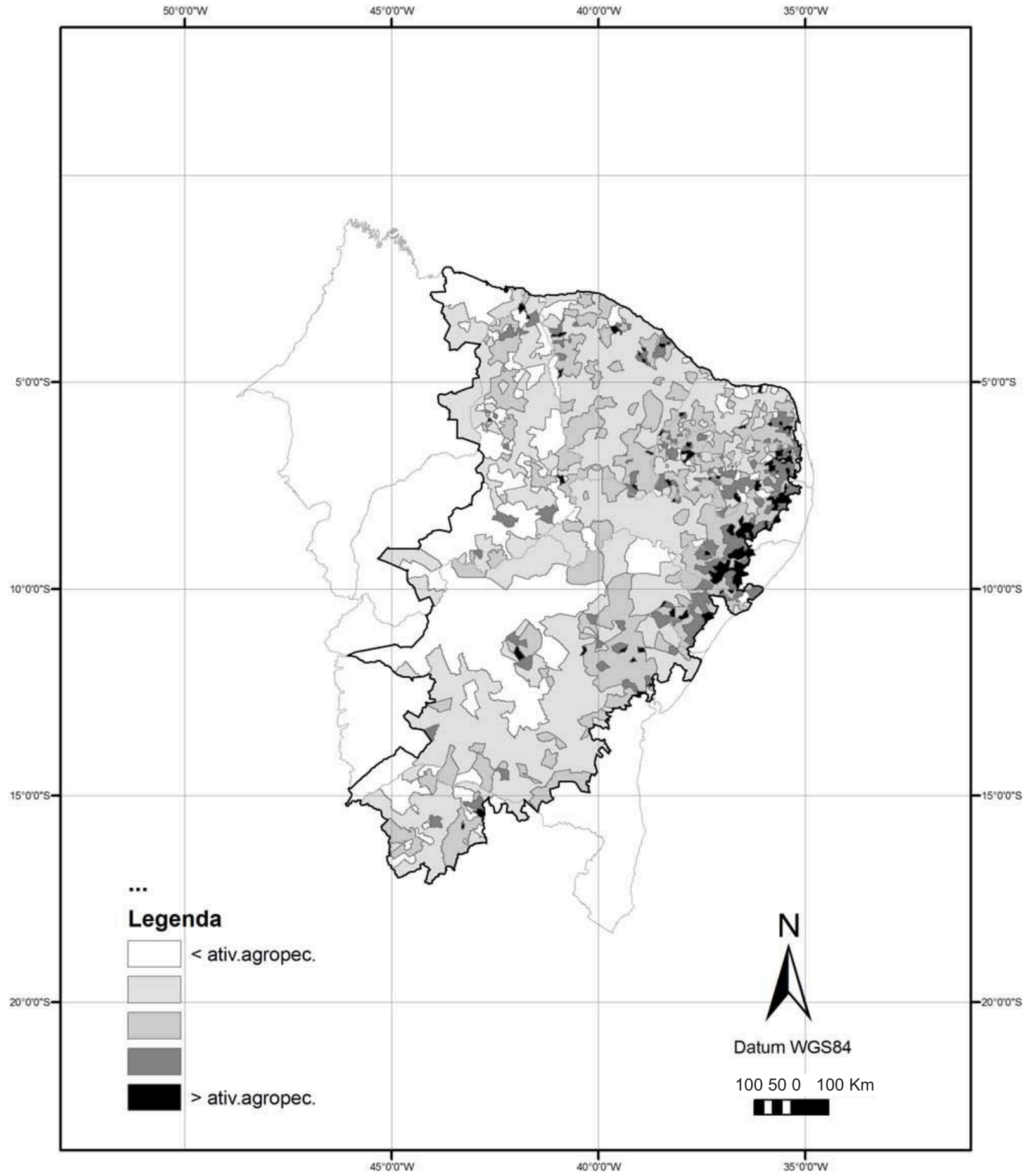

Figura 8. Intensidade da atividade agropecuária (S2). 
Interação de fatores biofísicos e antrópicos com a diversidade florística na indicação de áreas para conservação do bioma Caatinga Thomaz Correa e Castro Costa, Luciano José de Oliveira Accioly, Luciana Mara Temponi Oliveira, Maria Aparecida José de Oliveira, Daniel Pereira Guimarães

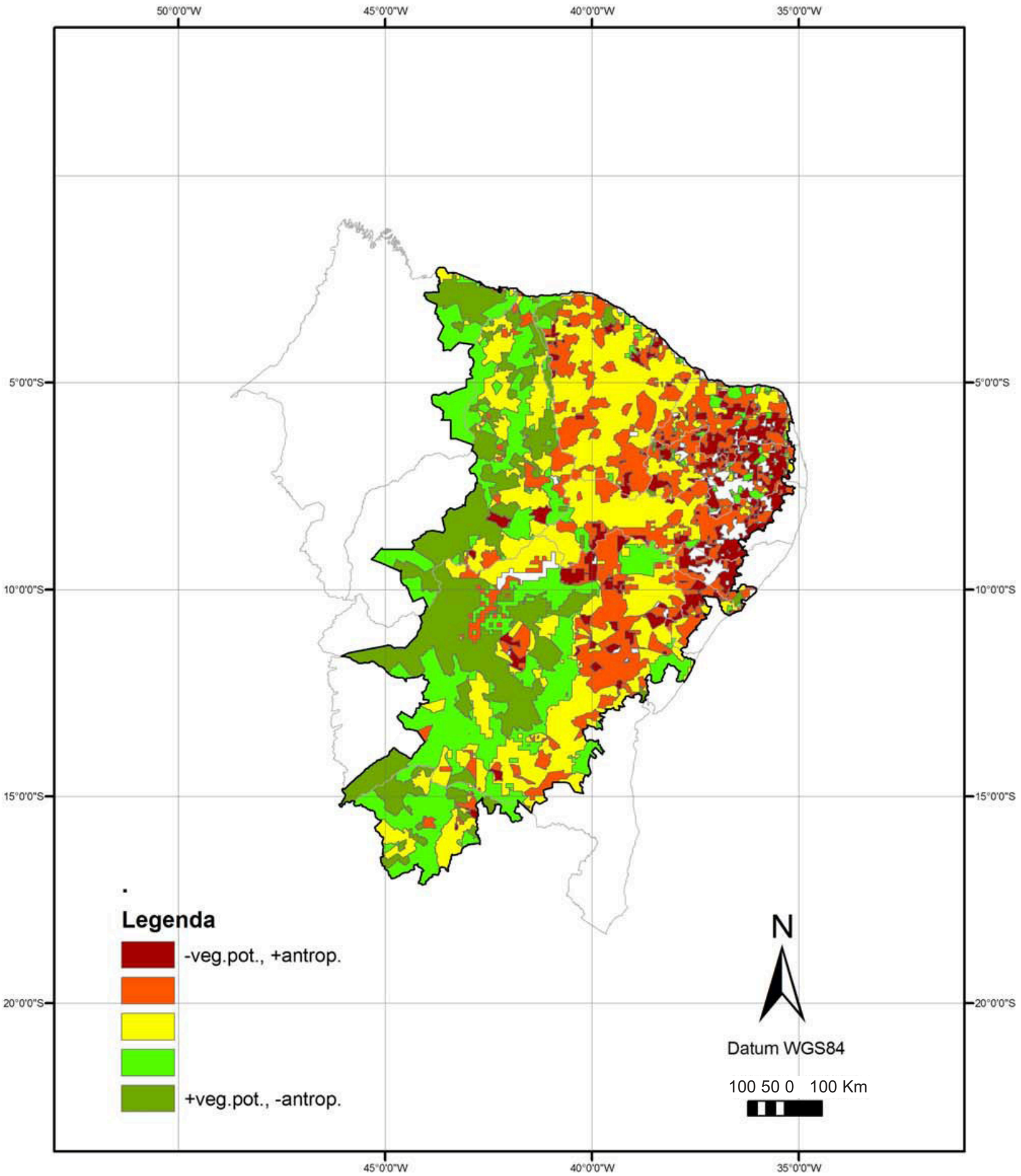

Figura 9. Indicação de áreas para conservação para o bioma Caatinga (Favorab.Diversid.- Intensid. Agropec.)/ (Favorab.Diversid.+ Intensid. Agropec.). Polígonos em branco correspondem às áreas com máxima intensidade agropecuária ou ao leito de rios. 


\section{Conclusão}

Foram encontradas relações empíricas significativas entre fatores físicos e características espectrais da vegetação com a diversidade florística no Bioma Caatinga.

A maior porção de áreas favoráveis para a criação de unidades de conservação encontra-se na extremidade oeste e sul do bioma Caatinga.

A modelagem da diversidade florística a partir de efeitos de favorecimento do ambiente e efeitos de pressão antrópica em escala regional, abre uma perspectiva para a sondagem de áreas com maior riqueza biológica para uma futura proteção legal, e a sondagem de áreas com maior degradação biológica para futuras intervenções de recuperação. O refinamento desta pesquisa propõe a melhoria da qualidade e a densidade espacial da informação disponibilizada, visando uma melhor correlação com os dados ambientais.

\section{Agradecimentos}

Esta pesquisa recebeu apoio dos projetos "Adaptação de métodos de geoinformação para avaliação do processo de desertificação do sertão do Seridó (RN/PB)" financiado pela Embrapa e "Adaptação de uma metodologia para a avaliação e o monitoramento de fragmentos de florestas com base na análise de misturas espectrais" financiado pelo CNPq.

\section{Referências}

ALCOFORADO FILHO, F.G. Composição florística e fitossociologia de uma área de Caatinga arbórea no Município de Caruaru, PE. 1993, 220p. Dissertação (Mestrado em Botânica) - Universidade Federal Rural de Pernambuco, Recife.

ALCOFORADO FILHO, F.G.; SAMPAIO, E.V.S.B.; RODAL, M.J.N. Florística e fitossociologia de um remanescente de vegetação caducifólia espinhosa arbórea em Caruaru, Pernambuco. Acta Botânica
Brasilica, São Paulo, v.17, n.2, p. 287-303, 2003 b.

AMORIM, I.L.; SAMPAIO, E.V.S.B.; ARAUJO, E.L. Flora e estrutura da vegetação arbustivo-arbórea de uma área de caatinga do Seridó, RN, Brasil. Acta Botânica Brasilica, São Paulo, v.19, n.3, p. 615-623, 2005.

ANDRADE-LIMA, D. The caatinga dominium. Revista Brasileira de Botânica, São Paulo, v.4, n.2, p.149-153, 1981.

ANDRADE, L.A.; PEREIRA, I.M.; LEITE, U.T.; BARBOSA, M.R.V. Análise da cobertura de duas fitofisionomias de caatinga, com diferentes históricos de uso, no Município de São João do Cariri, Estado da Paraíba. Cerne, Lavras, v.11, n.3, p. 253-262, 2005.

ARAUJO, E.L. \& FERRAZ, E.M.N. Processos ecológicos mantenedores da diversidade vegetal na caatinga: estado atual do conhecimento. V. ClaudinoSales (ed.). Ecossistemas brasileiros: manejo e conservação. Fortaleza, Expressão Gráfica e Editora, p. 115-128, 2003.

ARAÚJO, E.L.; SAMPAIO, E.V.S.B.; RODAL, M.J.N. Composição florística e fitossociologia de três áreas de Caatinga de Pernambuco. Revista Brasileira de Biologia, São Carlos, v. 55, n.4, p.595-607, 1995.

BRASIL. Ministério do Meio Ambiente. Secretaria de Recursos Hídricos. Programa de ação nacional de combate à desertificação e mitigação dos efeitos da seca PAN-BRASIL. Brasília, DF, 2004. 220p.

BRZEZIECKI, B.; KIENAST, F.; WILDI, O. A simulated map of the potential natural forest vegetation of Switzerland. Journal of Vegetation Science, Grangã, n.4, p. 499-508, 1993.

CARVALHO, G.H. Inventário florestal na Paraíba e no Rio Grande do Norte; III Contribuição para a determinação da reserva madeireira da Bacia do Rio Piranhas-Açu. Sudene Recursos Vegetais, Recife, n.3, p.1-14, 1975. 
Interação de fatores biofísicos e antrópicos com a diversidade florística na indicação de áreas para conservação do bioma Caatinga Thomaz Correa e Castro Costa, Luciano José de Oliveira Accioly, Luciana Mara Temponi Oliveira, Maria Aparecida José de Oliveira, Daniel Pereira Guimarães

COSTA, R.C.; ARAUJO, F.S.; LIMA-VERDE, L.W. Flora and life-form spectrum in an área of decíduous thorn woodland (caatinga) in northeastern, Brazil. Journal of Arid Environments, n. 68, p. 237-247, 2007.

COSTA, T.C.C.; ACCIOLY, L.J.O.; OLIVEIRA, M.A.J.; BURGOS, N. \& SILVA, F.H.B.B. Phytomass mapping of the "Seridó caatinga" vegetation by the plant area and the normalized difference vegetation indeces. Scientia Agricola, Piracicaba, v. 59: p. 707$715,2002$.

EASTMAN, J.R., JIN, W., KYEM, P.A.K., TOLEDANO, J. Raster procedures for multi-criteria, multi-objetive decisions. Photogrammetric Engineering and Remote Sensing, v. 61, n.5, p.539547, 1995.

FARIAS, R.R.S.; CASTRO, A.A.J.F. Fitossociologia de trechos da vegetação do complexo de Campo Maior, Campo Maior, PI, Brasil. Acta Botânica Brasílica, São Paulo, v. 18, n.4, p. 2-13, 2004.

FIGUEIREDO, M.A. A microrregião salineira NorteRio Grandense no domínio das caatingas. Coleção Mossoroense, Mossoró, 1987. 44p.

FISCHER, H.S. Simulating the distribution of plant communities in an Alpine landscape. Coenoses, v.5, n.1, p. 37-43, 1990.

Fundação Instituto Brasileiro de Geografia e Estatística. IBGE. Manual técnico da vegetação brasileira. Rio de Janeiro: IBGE, 1992. 92 p.

GOMES, M.A.F. A vegetação dos Cariris Velhos, no Estado da Paraíba. Vegetalia, São Paulo: UNESP, n.14, p. 1-27, 1980.

KAZMIERCZAK, M.L. Desenvolvimento de um algoritmo para modelar a susceptibilidade de desertificação no nordeste do Brasil: Algoritmo ISD[NEB] In: SIMPÓSIO BRASILEIRO DE SENSORIAMENTO REMOTO-SBSR, 9., 1998, Santos. Anais...São José dos Campos: Instituto Nacional de Pesquisas Espaciais, 1998. (CD-ROM).
LEAL, I. R.; SILVA, J. M.; TABARELLI, M.; LACHER JR.; T. E. Mudando o curso da conservação da biodiversidade na Caatinga do Nordeste do Brasil. In: Conservação Internacional do Brasil (ed.). Megadiversidade. Belo Horizonte, 2005. Vol. 1, p. 139-146. Disponível em: $\leq \mathrm{http}: / /$ www.conservacao.org/publicacoes/files/ 19 Leal et al.pdf $>$. Acesso em:10 de julho de 2009.

MACHADO, I.C.; LOPES, A.V. A polinização em ecossistemas de Pernambuco: uma revisão do estado atual do conhecimento. In: M. Tabarelli; J.M.C. Silva (orgs.). Diagnóstico da Biodiversidade de Pernambuco. Recife: Secretaria de Ciência, Tecnologia e Meio-Ambiente, Fundação Joaquim Nabuco e Editora Massangana. p. 583-596, 2002.

MARACAJA, P. B.; BATISTA, C. H. F.; SOUZA, A. H.; VASCONCELOS, W.E. Levantamento florístico e fitossociológico do estrato arbustivo-arbóreo de dois ambientes na vila Santa Catarina, Serra do Mel, RN. Revista de Biologia e Ciências da Terra, Campina Grande, v.3, n.2, p.25-32, 2003.

NASA. Homepage $\leq$ https://zulu.ssc.nasa.gov/mrsid/ mrsid.pl $>$. Acesso em 01 de março de 2005.

OLIVEIRA, L. M. T. Diagnóstico de fragmentos florestais nativos, em nivel de paisagem, em áreas sob influência da Veracruz Florestal Ltda., Eunápolis, $B A$. Dissertação (Mestrado em Ciências Florestais) Universidade Federal de Viçosa, Viçosa - MG, 74p. 1997.

OLIVEIRA, L. M. T. Estudo das regiões fitoecológicas brasileiras pela FAPAR/NDVI e relações com séries temporais de dados pluviométricos. Tese (Doutorado em Engenharia Civil) - Universidade Federal do Rio de Janeiro, COPPE, Rio de Janeiro, 208 p. 2008.

PEBESMA, E. J. Gstat, a program for geostatistical modelling, prediction and simulation. Copyright 1992,1998 (C)

PRADO, D. 2003. As caatingas da América do Sul. 
In: I.R. Leal, M. Tabarelli \& J.M.C. Silva (eds.). Ecologia e conservação da Caatinga. p. 3-73. Editora Universitária, Universidade Federal de Pernambuco, Recife, Brasil.

ROCHA, P.L.; QUEIROZ, L.P.; PIRANI, J.R. Plant species and habitat structure in a sand dune field in the Brazilian Caatinga: a homogeneous habitat harbouring an endemic biota. Revista Brasileira de Botanica, São Paulo, v. 27, n. 4, p. 739-755, out-dez, 2004.

RODAL, M.J.N. Fitossociologia da vegetação arbustivo-arbórea em quatro áreas de Caatinga em Pernambuco. 1992, 224p. Tese (Doutorado em Ciências) - Universidade Estadual de Campinas, Campinas. 1992.

SAMPAIO, E.V.S.B. 2003. Caracterização da caatinga e fatores ambientais que afetam a ecologia das plantas lenhosas. p. 129-142. In: V.C. Sales (ed.). Ecossistemas brasileiros: manejo e conservação. Fortaleza, Expressão Gráfica e Editora.

SANTANA, J.A.S.; SOUTO, J.S. Diversidade e estrutura fitossociológica da Caatinga na Estação Ecológica do Seridó-RN. Revista de Biologia e Ciências da Terra, Campina Grande, v.6, n.2, p 232242, 2006.

SANTOS, M.F.A.V. Características dos solos e da vegetação em sete áreas de Parnamirim-Pernambuco. 1987, 230p. Dissertação (Mestrado em Botânica) Universidade Federal Rural de Pernambuco, Recife. 1987.

SIEGEL, S. Nonparametric statistics for the behavioral sciences. New York: McGraw-Hill, 1956. $350 \mathrm{p}$.

SILVA, I.H. Correlações entre a vegetação e tipos distintos de solos do Baixio de Irecê, Bahia.1991, 104p. Dissertação (Mestrado em Botânica) Universidade Federal Rural de Pernambuco, Recife. 1991.
SILVA, J. M. C. da; TABARELLI, M.; FONSECA, M. T. da; LINS, L. V. (Org.). Biodiversidade da caatinga: áreas e ações prioritárias para a conservação. Brasília, DF: Ministério do Meio Ambiente: Universidade Federal de Pernambuco, 2004. $382 \mathrm{p}$.

STÖCKLI, R., 2004, Modeling and observation of seasonal land-surface heat and water exchanges at local and catchments scales over Europe. Thesis (Doctor in Natural Sciences). Swiss Federal Institute of Technology, ETH. 155p.

TAVARES, S.; PAIVA, F.A.F.; SOUZA TAVARES, E.J.; CARVALHO, G.H. Inventário florestal na Paraíba e no Rio Grande do Norte; I Estudo preliminar das matas remanescentes do Vale do Piranhas. Sudene Recursos Vegetais, Recife n.4, p.1-31, 1975.

TAVARES, S.; PAIVA, F.A.F.; SOUZA TAVARES, E.J.; CARVALHO, G.H.; LIMA, J.L.S. Inventário florestal de Pernambuco. Estudo preliminar das matas remanescentes dos Municípios de Ouricuri, Bodocó, Santa Maria da Boa Vista e Petrolina. Boletim de Recursos Naturais da Sudene, Recife, v.8, p. 149-194, 1970.

TAVARES, S.; PAIVA, F.A.F.; SOUZA TAVARES, E.J.; LIMA, J.L.S. CARVALHO, G.H. Inventário florestal de Pernambuco. Estudo preliminar das matas remanescentes do Município de São José de Belmonte. Boletim de Recursos Naturais da Sudene, Recife v.7, n.1-4, p.113-139, 1969a.

TAVARES, S.; PAIVA, F.A.F.; SOUZA TAVARES, E.J.; LIMA, J.L.S. Inventário florestal do Ceará. IIEstudo preliminar das matas remanescentes do Município de Tauá. Boletim de Recursos Naturais da Sudene, Recife v.12, n.2, p.5-19, 1974a.

TAVARES, S.; PAIVA, F.A.F.; SOUZA TAVARES, E.J.; LIMA, J.L.S. Inventário florestal do Ceará. Estudo preliminar das matas remanescentes do Município de Quixadá. Boletim de Recursos Naturais da Sudene, Recife v.7, n.1-4, p.93-111, 1969b.

Sociedade \& Natureza, Uberlândia, 21 (1): 19-37, ABR. 2009 
Interação de fatores biofísicos e antrópicos com a diversidade florística na indicação de áreas para conservação do bioma Caatinga

Thomaz Correa e Castro Costa, Luciano José de Oliveira Accioly, Luciana Mara Temponi Oliveira, Maria Aparecida José de Oliveira, Daniel Pereira Guimarães

TAVARES, S.; PAIVA, F.A.F.; SOUZA TAVARES, E.J.; LIMA, J.L.S. Inventário florestal do Ceará. IIIEstudo preliminar das matas remanescentes do Município de Barbalha. Boletim de Recursos Naturais da Sudene, Recife v.12, n.2, p. 20-46, 1974 b.

TRIANTAPHYLLOU, E.; MANN, S.H. A computational evaluation of the original and revised analytic hierarchy process. Computers and industrial engineering. V. 26, n.3, p.609-618,1994. 